\title{
Geographic distribution of cryptococcosis in the state of Mato Grosso do Sul, Central-West Brazil region
}

Marilene Rodrigues Chang, Rosianne Assis de Sousa Tsujisaki, Maína de Oliveira Nunes, Gláucia Moreira Espíndola Lima, Amanda Borges Colman, Dario Corrêa Júnior, Anamaria Mello Miranda Paniago, Simone Schneider Weber, Rinaldo Poncio Mendes

Federal University of Mato Grosso do Sul, Campo Grande-MS, Brazil

\section{INTRODUCTION}

Cryptococcosis is a systemic mycosis of global distribution caused by species of the complexes Cryptococcus neoformans and Cryptococcus gattii that can be found in soil, bird droppings, tree hollows and decaying wood.2,3 The Central-West Brazil region presents favorable environmental conditions (tropical of altitude climate and average temperature between $20^{\circ} \mathrm{C}$ and $25^{\circ} \mathrm{C}$ ) for the development of these fungi. The Mato Grosso do Sul state is home to $65 \%$ of the Pantanal, an incredible biodiversity scenario with rich fauna and flora, ${ }^{4}$ where birds migrate that can influence the geographical distribution of Cryptococcus spp. in the region.

\section{OBJECTIVES}

The objective of this study was to document cases of cryptococcosis in Mato Grosso do Sul, Brazil according to the cities and to determine the molecular types of Cryptococcus spp involved.

\section{METHODS}

Were included Cryptococcus spp. isolated from different clinical specimens isolated of inpatients at University Hospital of the Federal University of Mato Grosso do Sul from 1997 to 2016. The molecular types were identified by the URA5-RFLP method. ${ }^{5}$

Figure 1 - Distribution of molecular types of Cryptococcus in the state of Mato Grosso do Sul and other regions of Brazil

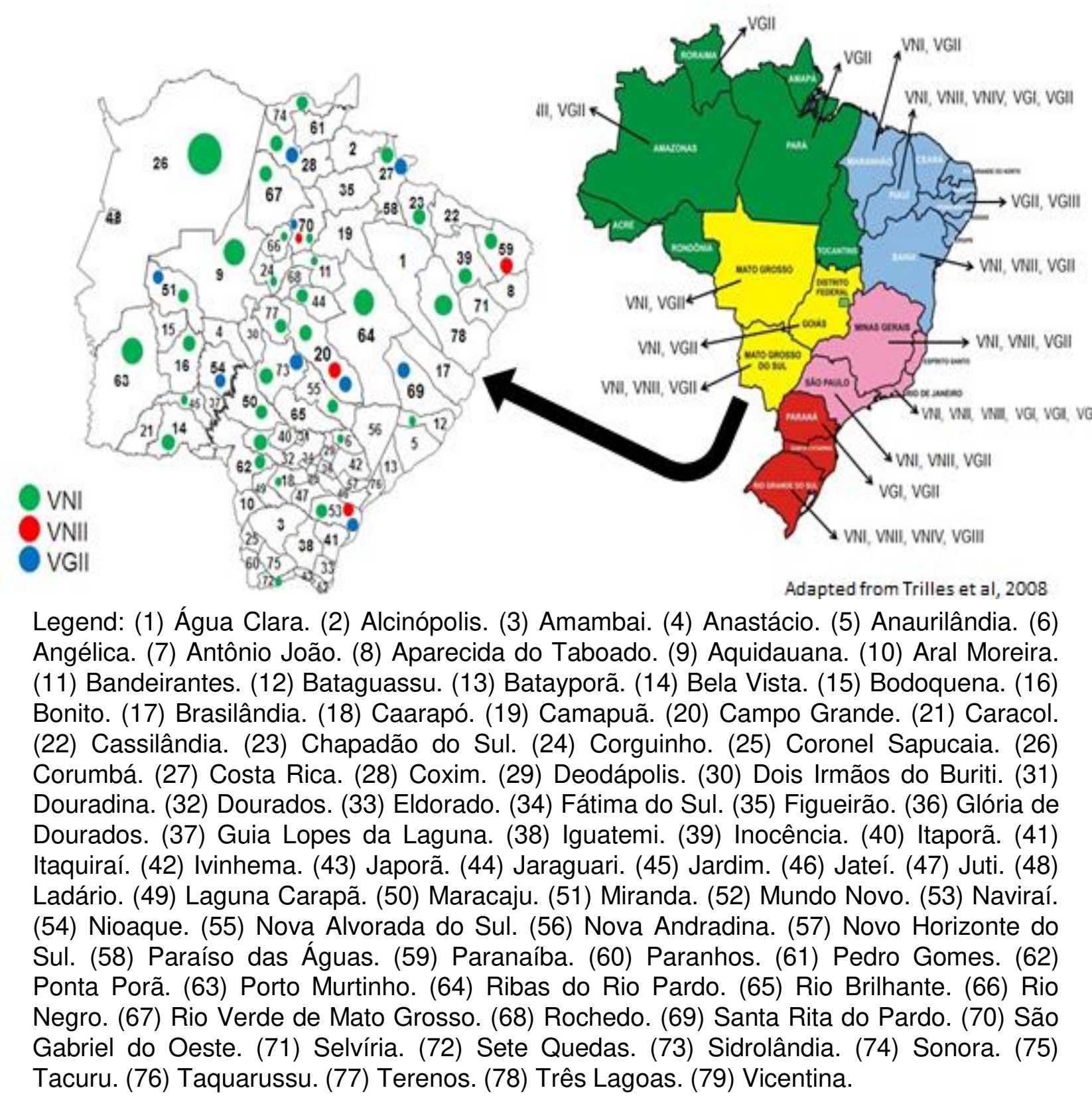

\section{RESULTS}

Of 79 cities in the Mato Grosso do Sul state, 35 $(44.3 \%)$ had at least one case of cryptococcosis. Of the 220 cases studied, 150 (68.2\%) were from Campo Grande, capital of Mato Grosso do Sul (126; 84\% C. neoformans VNI, 9; 6\% C. neoformans VNII and 15; 10\% C. deuterogattii). Eight cases of cryptococcosis were identified in the Pantanal region (Aquidauana, Anastácio, Corumbá, Ladário and Miranda), seven by $C$. neoformans VNI and one by $C$. deuterogattii. The found molecular types are similar to other Brazillian regions (Figures 1 and 2). The Figure 3 shows the Cryptococcosis cases grouped into each three years. Thee patients had a mean age of 40 years and consisted mostly of men $(75.7 \%)$. Most of the Cryptococcus isolates were obtained from patients with human immunodeficiency virus (HIV) and included 169 (97.1\%) and five (2.9\%) isolates of $C$. neoformans and $C$. gattii complexes, respectively.

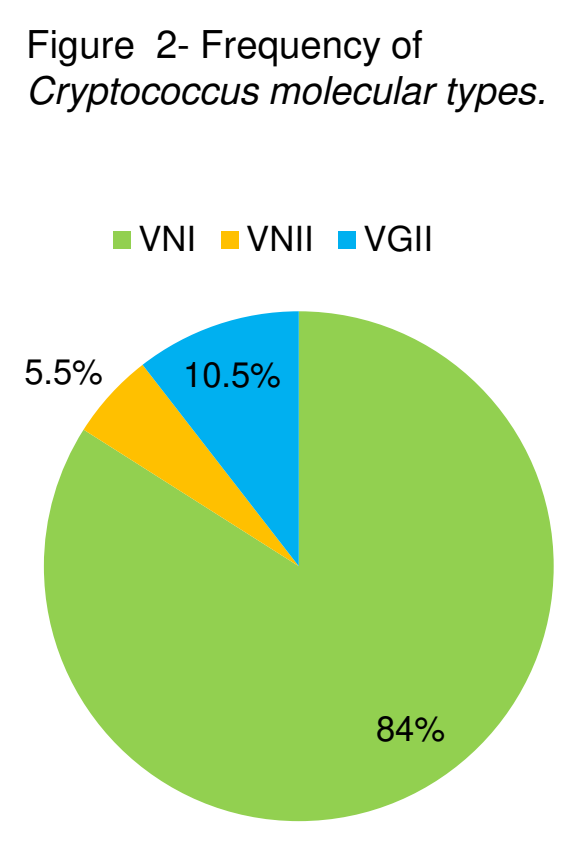

Figure 3- Cryptococcosis cases grouped into each three years

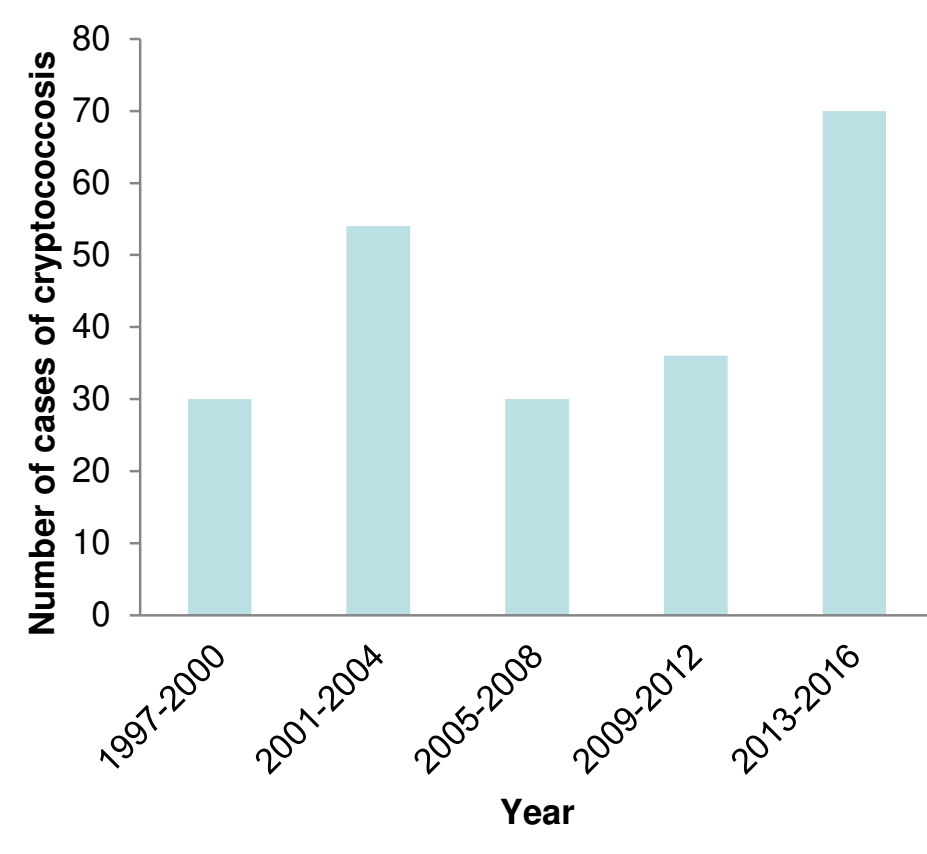

CONCLUSION

The present study documents the occurrence of cryptococcosis, which is mainly caused by $C$. neoformans VNI in Mato Grosso do Sul, Brazil, with probable autochthonous cases in the Brazilian Pantanal, the world's largest tropical wetland and a biome where cryptococcosis has not yet been explored.

\section{REFERENCES}

KWON-CHUNG, K. J. et al. The case for adopting the "species complex" nomenclature for the etiologic agents of cryptococcosis. American Society for Microbiology, v. 2, n. 1, p. 1-7, Jan./Feb. 2017.

2. ELLIS, D.; PFEIFFER, T. The ecology of Cryptococcus neoformans. European Journal of Epidemiology, v. 8, n.3, p. 321-325, May 1992.

3. LAZÉRA, M. S.; SALMITO CAVALCANTI, M. A.; LONDERO, A. T.; TRILLES, L; NISHIKAWA, M. M.; WANKE, B. Possible primary ecological niche of Cryptococcus neoformans. Medical Mycology, v. 38, n. 5, p. 379-383, Oct. 2000.

4. Governo do Estado Mato Grosso do Sul. Turismo MS. Perfil MS. Available in <http://www.turismo.ms.gov.br/conheca-ms/perfil-ms/>. Access in: 24 fev. 2018.

5. MEYER, W. et al. Molecular typing of IberoAmerican Cryptococcus neoformans isolates. Emerging Infectious Diseases, v. 9, n. 2, p. 189-195, Feb. 2003. 